\title{
Derivation of anthropometric cut-off levels to define CVD risk in Sri Lankan adults
}

\author{
P. Katulanda ${ }^{1,2 *}$, M. A. R. Jayawardena ${ }^{1}$, M. H. R. Sheriff ${ }^{1}$ and D. R. Matthews ${ }^{2}$ \\ ${ }^{1}$ Diabetes Research Unit, Department of Clinical Medicine, Faculty of Medicine, University of Colombo, Kynsey Road, \\ Colombo 8, Sri Lanka \\ ${ }^{2}$ Oxford Centre for Diabetes, Endocrinology and Metabolism, University of Oxford, Oxford, UK
}

(Received 25 January 2010 - Revised 26 June 2010 - Accepted 15 August 2010 - First published online 17 December 2010)

\section{Abstract}

Obesity is associated with increased cardiovascular risk. Anthropometric cut-off values derived for Caucasians may not be applicable to other populations. The main objective of the present study was to derive population-specific anthropometric cut-off values to define high CVD risk for Sri Lankan adults. A nationally representative sample of 4474 non-institutionalised adults aged $\geq 18$ years was analysed. Cut-off values to provide optimum sensitivity and specificity were derived using receiver-operating characteristic curve analysis. BMI, waist circumference (WC), waist-to-hip ratio (WHR), blood pressure and overnight fasting venous blood samples were collected to measure glucose, HDL-cholesterol and TAG. An oral glucose tolerance test was also performed. The results suggested that the age-adjusted BMI, WC and WHR were significantly associated with all cardiovascular risk factors $(P<0 \cdot 001)$. Cut-off values for BMI, WC and WHR for males were $20.7 \mathrm{~kg} / \mathrm{m}^{2}, 76.5 \mathrm{~cm}$ and 0.89 , respectively. The respective values for females were $22 \cdot 0 \mathrm{~kg} / \mathrm{m}^{2}, 76 \cdot 3 \mathrm{~cm} \mathrm{and} 0.85$. The common cut-off value for BMI for males and females was $21.5 \mathrm{~kg} / \mathrm{m}^{2}$. Similarly, WC and WHR cut-off values for both males and females were $76.3 \mathrm{~cm}$ and 0.87 , respectively. The Asian and Caucasian anthropometric cut-off levels showed lower sensitivity and higher false negative percentage compared with newly derived cut-off levels. In conclusion, BMI, WC and WHR were all associated with increased CVD risk. We propose the following anthropometric cut-off points to determine high CVD risk level for Sri Lankan adults: $\mathrm{BMI} \geq 21.5 \mathrm{~kg} / \mathrm{m}^{2}$, WC $\geq 76 \mathrm{~cm}$ and WHR $\geq 0.85$ (women) and 0.90 (men).

\section{Key words: BMI: Waist circumference: Metabolic risk factors: CVD risk: Obesity: Sri Lanka}

Obesity has become a worldwide epidemic and is on the rise both in developed and developing countries ${ }^{(1,2)}$. According to the WHO's recent global estimations, over one billion adults are overweight $\left(\mathrm{BMI} \geq 25 \mathrm{~kg} / \mathrm{m}^{2}\right.$ ) and nearly 300 million are obese $\left(\mathrm{BMI} \geq 30 \mathrm{~kg} / \mathrm{m}^{2}\right.$ ) worldwide $^{(3)}$. Unequivocal evidence exists on the association of overweight and obesity with adverse medical, psychological, social and economical consequences ${ }^{(4)}$. Moreover, obesity significantly increases the risk of morbidity and mortality in many common disorders such as diabetes mellitus, CVD, musculoskeletal disorders and certain malignancies ${ }^{(5)}$. Obesity is also known to reduce quality of life and life expectancy ${ }^{(6)}$.

Abdominal adiposity, which is also called central obesity, is associated with a higher risk of the development of chronic diseases such as diabetes mellitus ${ }^{(7)}$ and $\mathrm{CVD}^{(8)}$. BMI is widely used to assess obesity worldwide ${ }^{(9)}$. However, it may not be a good index to measure body-fat distribution, particularly in those predominantly having abdominal obesity ${ }^{(10)}$. Many studies have shown waist circumference (WC) to be a better predictor of abdominal obesity and to be associated with higher CVD risk ${ }^{(11)}$. However, some studies have demonstrated waist-to-hip ratio (WHR) to be superior to $\mathrm{BMI}$ and $\mathrm{WC}^{(12)}$.

Differences exist in the susceptibility to adiposity and its adverse metabolic and cardiovascular complications between different ethnic groups ${ }^{(13)}$. South Asians (SA) have a higher prevalence of obesity associated with chronic diseases such as diabetes mellitus and CVD at a relatively lower $\mathrm{BMI}^{(14-16)}$.

The anthropometric cut-off values widely used for defining overweight and obesity are based on data from Caucasians $^{(9)}$. Due to ethnic-specific differences in susceptibility to obesity and its health risks, the WHO has suggested adopting population-specific anthropometric cut-off values for different populations ${ }^{(17)}$. However, there are very few published data for SA countries with regard to anthropometric cut-off values ${ }^{(18,19)}$. There are

Abbreviations: SA, South Asians; WC, waist circumference; WHR, waist-to-hip ratio. 
no published data on anthropometric cut-off values for the Sri Lankan adult population. The primary objective of the present study was to define population-specific anthropometric cut-off values to define CVD risk for Sri Lankan adults.

\section{Subjects and methods}

Data from a nationally representative epidemiological study (Sri Lanka Diabetes and Cardiovascular Study) were used in deriving ethnic-specific cut-off values. The Sri Lanka Diabetes and Cardiovascular Study was a crosssectional population study conducted between August 2005 and September 2006. The present study was conducted according to the guidelines laid down in the Declaration of Helsinki and was approved by the Review Committee, Faculty of Medicine, University of Colombo, Sri Lanka. Written informed consent was obtained from all participants before data collection. Detailed sampling has previously been described ${ }^{(20)}$. A multi-stage random cluster sampling method was used to select a sample of 5000 non-institutionalised adults aged $\geq 18$ years from seven of the nine provinces in Sri Lanka. A total of 4474 (males 1767 and females 2707) subjects participated in the study.

\section{Measurements}

Anthropometric measurements were performed by trained nurses adhering to the WHO guidelines using calibrated equipment $^{(21)}$. Height was recorded as the maximum distance to the uppermost position on the head from the heel to the nearest $0 \cdot 1 \mathrm{~cm}$, with the individual standing barefoot and in full inspiration using Harpenden pocket stadiometers (Chasmors Limited, London, UK). Body weight was measured in indoor light clothing to the nearest $0 \cdot 1 \mathrm{~kg}$ using a SALTER 920 digital weighing scale (Salter Limited, Tonbridge, Kent, UK). WC was measured midway between the iliac crest and the lower rib margin at the end of normal expiration using a plastic flexible tape to the nearest $0 \cdot 1 \mathrm{~cm}$. Similarly, hip circumference was also measured as the widest distance of the buttocks in the inter-trochantric level to the nearest $0 \cdot 1 \mathrm{~cm}$. BMI was calculated as weight in $\mathrm{kg}$ divided by height in $\mathrm{m}^{2}\left(\mathrm{~kg} / \mathrm{m}^{2}\right)$.

Blood pressure was measured twice with an interval of at least $10 \mathrm{~min}$ rest in a seated position using an Omron IA2 digital blood pressure apparatus (Omron Healthcare, Asia-Pacific Region, Singapore); the two readings of blood pressure were used for both systolic and diastolic blood pressure in the analysis.

Overnight fasting venous blood samples were collected to measure HDL-cholesterol, TAG and glucose. The cholesterol and TAG were measured by an enzymatic colorimetric method in a RxDaytona ${ }^{\mathrm{TM}}$ chemical analyser
(Randox Laboratories Limited, Crumlin, Antrim, UK). Participants who did not have a history of diagnosed diabetes ( $n$ 4084) had an oral glucose tolerance test. Blood specimens were processed at the field centres, were kept in ice and stored at $-20^{\circ} \mathrm{C}$ within $6-12 \mathrm{~h}$ of collection. Chemical analyses were performed in a central laboratory in Colombo.

\section{Definitions}

Individual 'obesity-related CVD risk factors' were defined as shown below according to the International Diabetes Federation criteria for the diagnosis of the metabolic syndrome ${ }^{(22)}$ :

(1) Raised TAG: $\geq 1500 \mathrm{mg} / 1 \quad(1.7 \mathrm{mmol} / \mathrm{l})$ or specific treatment for hypertriacylglycerolaemia.

(2) Low HDL-cholesterol: $<400 \mathrm{mg} / 1 \quad(1.03 \mathrm{mmol} / \mathrm{l})$ in males and $<500 \mathrm{mg} / 1(1.29 \mathrm{mmol} / \mathrm{l})$ in females or specific treatment for low HDL-cholesterol.

(3) Raised blood pressure: systolic blood pressure $\geq 130 \mathrm{mmHg}$ or diastolic blood pressure $\geq 85 \mathrm{mmHg}$ or treatment for previously diagnosed hypertension.

(4) Dysglycaemia: fasting plasma glucose $\geq 1000 \mathrm{mg} / 1$ $(5.6 \mathrm{mmol} / \mathrm{l})$ and/or $2 \mathrm{~h}$ post-oral glucose tolerance test glucose $\geq 7.8 \mathrm{mmol} / 1$.

Obesity-related high CVD risk was defined as the presence of two or more of these factors (except the obesity variable) and was considered as the dependent variable in defining anthropometric cut-off values.

\section{Statistical analysis}

Age-adjusted linear regression and correlation analysis was performed to determine the association of anthropometric variables with blood glucose, blood pressure, HDLcholesterol and TAG taken as continuous variables Receiver-operating characteristic curve analysis ${ }^{(23)}$ was performed with 'obesity-related high CVD risk' as the dependent variable to define the cut-off points for BMI, WC and WHR. The same procedure was performed using individual risk factors as dependent variables.

The individual anthropometric values with the highest combined sensitivity and specificity to define 'obesityrelated high CVD risk' were considered the optimal cut-off levels. Finding the point that had the highest sensitivity and specificity was made easier by plotting the product of sensitivity and specificity against the anthropometric values. Binary logistic regression analysis was performed with 'obesity-related high CVD risk' as the dependent variable and the (age-adjusted) anthropometric indices as covariates (as categorical variables) to confirm that the cut-off values selected by receiver-operating characteristic curve analysis were associated with statistically significant high risk. For binary logistic regression, BMI was categorised starting from $\leq 16 \mathrm{~kg} / \mathrm{m}^{2}$ using 
intervals of $2 \cdot 5$, WC from $\leq 60 \mathrm{~cm}$ with intervals of $5 \mathrm{~cm}$ and WHR starting from $\leq 0.7$ with intervals of 0.05 . The prevalence of obesity based on the newly derived and existing cut-off values and their sensitivity, specificity, positive predictive value and negative predictive value to identify 'obesity-related high CVD risk factors' were compared with the existing cut-off values for Caucasians and proposed cut-off values for Asians.

\section{Results}

\section{Characteristics of the study sample}

Characteristics of the study variables are summarised in Table 1 . The mean age of males was $46 \cdot 3$ (SD 15.8) years and that of females was $46 \cdot 0$ (SD 14.6) years. Males had significantly higher WC, WHR, mean systolic blood pressure and TAG. Females had significantly higher BMI, $2 \mathrm{~h}$ plasma glucose, total cholesterol, LDL-cholesterol and HDL-cholesterol.

\section{Association of anthropometric measurements and cardiovascular risk factors in Sri Lankan adults}

The age-adjusted BMI, WC and WHR had a significant correlation with individual CVD risk factors analysed as continuous variables $(P<0.0001$ for all correlations). However, the correlation coefficient was less than 0.3 for most associations (Table 2). In men, the correlation coefficients for total cholesterol and WC, and TAG for all three indicators, and that between diastolic blood pressure and WC were $>0 \cdot 3$. In women, the correlation coefficients between diastolic blood pressure, and BMI and WC were $>0 \cdot 3$. The associations of the anthropometric indices with HDL-cholesterol were negative.

Table 1. Demographic, anthropometric and metabolic profiles of the study sample

(Mean values and standard deviations)

\begin{tabular}{|c|c|c|c|c|c|}
\hline \multirow[b]{2}{*}{ Characteristics } & \multicolumn{2}{|c|}{ Male } & \multicolumn{2}{|c|}{ Female } & \multirow[b]{2}{*}{$P^{*}$} \\
\hline & Mean & SD & Mean & SD & \\
\hline Age (years) & $46 \cdot 3$ & $15 \cdot 8$ & $46 \cdot 0$ & $14 \cdot 6$ & 0.51 \\
\hline BMI $\left(\mathrm{kg} / \mathrm{m}^{2}\right)$ & $21 \cdot 1$ & 3.7 & $22 \cdot 8$ & 4.5 & $<0.001$ \\
\hline$W C(\mathrm{~cm})$ & $78 \cdot 1$ & 11.0 & $76 \cdot 7$ & $12 \cdot 1$ & $<0.001$ \\
\hline WHR & 0.89 & 0.07 & 0.85 & 0.08 & $<0.001$ \\
\hline $\mathrm{SBP}(\mathrm{mmHg})$ & 128.9 & $19 \cdot 4$ & $125 \cdot 9$ & $19 \cdot 9$ & $<0.001$ \\
\hline $\mathrm{DBP}(\mathrm{mmHg})$ & $75 \cdot 2$ & 11.6 & 75.4 & $11 \cdot 1$ & 0.575 \\
\hline $\mathrm{FBG}(\mathrm{mmol} / \mathrm{l})$ & 5.09 & 1.54 & 5.06 & 1.61 & 0.513 \\
\hline $\begin{array}{l}2 \mathrm{~h} \text { Plasma } \\
\text { glucose }(\mathrm{mmol} / \mathrm{l})\end{array}$ & $5 \cdot 74$ & $2 \cdot 88$ & $6 \cdot 39$ & $2 \cdot 82$ & $<0.001$ \\
\hline $\mathrm{TC}(\mathrm{mmol} / \mathrm{l})$ & $202 \cdot 1$ & $42 \cdot 9$ & $209 \cdot 8$ & $43 \cdot 8$ & $<0.001$ \\
\hline LDL (mmol/l) & $130 \cdot 8$ & $36 \cdot 7$ & 138.6 & 37.9 & $<0.001$ \\
\hline $\mathrm{HDL}(\mathrm{mmol} / \mathrm{l})$ & 44.6 & $10 \cdot 4$ & $48 \cdot 2$ & $10 \cdot 6$ & $<0.001$ \\
\hline $\mathrm{TAG}(\mathrm{mmol} / \mathrm{l})$ & $132 \cdot 8$ & 73.5 & 114.5 & $60 \cdot 8$ & $<0.001$ \\
\hline
\end{tabular}

WC, waist circumference; WHR, waist-to-hip ratio; SBP, systolic blood pressure; DBP, diastolic blood pressure; FBG, fasting blood glucose; TC, total cholesterol. ${ }^{*} t$ Test for equality of means between males and females.

\section{Anthropometric cut-off values for Sri Lankan adults in} predicting high obesity-associated CVD risk

The cut-off values derived from receiver-operating characteristic curve analysis for BMI, WC and WHR are shown in Table 3. The cut-off values for BMI, WC and WHR for males were $20.7 \mathrm{~kg} / \mathrm{m}^{2}, 76.5 \mathrm{~cm}$ and 0.89 , respectively. The respective values for females were $22.0 \mathrm{~kg} / \mathrm{m}^{2}$, $76.3 \mathrm{~cm}$ and 0.85 . The common cut-off value for BMI for males and females was $21.5 \mathrm{~kg} / \mathrm{m}^{2}$. Similarly, the WC and WHR cut-off values for both males and females were $76.3 \mathrm{~cm}$ and 0.87 , respectively.

The cut-off values of anthropometric indices for the prediction of diabetes were higher than those for obesityrelated CVD risk as well as for all other risk factors alone (Table 3). The area under the curve for the prediction of low HDL-cholesterol was lower than that for all other risk factors and for obesity-related CVD risk.

\section{Anthropometric indices and CVD risk}

In both males and females, the OR for BMI in predicting obesity-related high CVD risk had a continuous rise starting from lower BMI levels and became significant at the BMI category $18.50-20.99 \mathrm{~kg} / \mathrm{m}^{2}$ (Table S1, supplementary material for this article, can be found at http://www. journals.cambridge.org/bjn). The OR had an approximately linear increase starting from the lowest BMI category. The highest $\mathrm{OR}$ in men was in the highest BMI category $\left(>28.5 \mathrm{~kg} / \mathrm{m}^{2}\right)$, but in females, it was in the category below the highest $\left(26 \cdot 00-28 \cdot 49 \mathrm{~kg} / \mathrm{m}^{2}\right)$. The trend was significant at $P<0.001$ for both sexes. Similarly, the OR for WC in predicting obesity-related CVD risk showed a continuous increase (Table S2, supplementary material for this article, can be found at http://www.journals. cambridge.org/bjn) starting with the lowest WC level in both males and females. The trend was significant at $P<0.001$ for both sexes. In both males and females, the OR for WHR increased starting from the lowest level $(<0.75)$ (Table S3, supplementary material for this article, can be found at http://www.journals.cambridge.org/bjn). However, the level at which there was a significant difference in males was higher than that for females (males: 0.91-0.95 and females: 0.75-0.80).

The sensitivity, specificity, positive predictive value and negative predictive value of the newly derived anthropometric cut-off values were compared with the global cut-off values and those proposed for Asians by the $\mathrm{WHO}^{(9)}$ recently (Table 4 ). The WHO-recommended BMI cut-off values for overweight for SA and Caucasians are 23 and $25 \mathrm{~kg} / \mathrm{m}^{2}$, respectively ${ }^{(9)}$. The sensitivity to detect obesity-related high CVD risk for the newly derived cutoff values, Asian cut-off values and that for Caucasians was 66, 52 and 34\%, respectively. The specificity had an inverse relationship, with it being $88 \%$ for a BMI cut-off value of $25 \mathrm{~kg} / \mathrm{m}^{2}$, compared with a specificity of $67 \%$ for a BMI cut-off value of $21.5 \mathrm{~kg} / \mathrm{m}^{2}$. Similarly, the positive predictive value increased with a higher cut-off value at the expense of the negative predictive value. 
Table 2. Age-adjusted correlation coefficients $(r)$ between anthropometric indices and blood glucose, blood pressure and lipids

\begin{tabular}{|c|c|c|c|c|c|c|}
\hline & \multicolumn{2}{|c|}{$\mathrm{BMI}^{*}$} & \multicolumn{2}{|c|}{$W C^{*}$} & \multicolumn{2}{|c|}{ WHR $^{*}$} \\
\hline & Male & Female & Male & Female & Male & Female \\
\hline Fasting plasma glucose & 0.19 & 0.13 & 0.23 & 0.14 & 0.20 & 0.12 \\
\hline $2 \mathrm{~h}$ Plasma glucose & 0.24 & 0.20 & 0.25 & 0.20 & 0.22 & $0 \cdot 15$ \\
\hline HDL-cholesterol & $-0 \cdot 17$ & -0.22 & -0.16 & -0.23 & -0.11 & -0.16 \\
\hline TAG & 0.33 & 0.28 & 0.35 & 0.27 & 0.32 & 0.19 \\
\hline Total cholesterol & 0.30 & 0.18 & 0.32 & 0.17 & 0.27 & $0 \cdot 11$ \\
\hline Systolic blood pressure & 0.25 & 0.28 & 0.24 & 0.26 & 0.18 & $0 \cdot 15$ \\
\hline Diastolic blood pressure & 0.29 & 0.35 & 0.31 & 0.32 & 0.24 & 0.19 \\
\hline
\end{tabular}

WC, waist circumference; WHR, waist-to-hip ratio.

* Correlation coefficient values were significant $(P<0.0001)$ for all associations in both men and women.

The cut-off values recommended for Asians by the International Diabetes Federation for WC are $80 \mathrm{~cm}$ for females and $90 \mathrm{~cm}$ for males ${ }^{(22)}$. However, according to the Sri Lankan data, the cut-off values for males and females did not differ very much from each other (male $76.5 \mathrm{~cm}$ and female $76.3 \mathrm{~cm}$ ) (Table 3). Therefore, a cut-off value of $75 \mathrm{~cm}$ was considered for both males and females, considering the practicability of a single cut-off value for public health action. For males, the sensitivities of waist cut-off values of 75,80 and $90 \mathrm{~cm}$ were 76,62 and $27 \%$, respectively. For females, the sensitivities of the same cut-off points were 72,57 and $25 \%$.

The WHO has defined a high WHR for males as $>1.0$ and for females as $>0.85$. A WHR of $>1.0$ had a sensitivity of $6.7 \%$ for males, whereas the cut-off value of 0.90 (round up value of 0.89 ) gave a sensitivity of $60 \%$ in males. For females, the WHO-recommended cut-off point of $>0.85$ was similar to the derived value and had a sensitivity of $67 \%$ and a specificity of $60 \%$.

\section{Discussion}

This is the first attempt to identify anthropometric cut-off values to predict obesity-related CVD risk for indigenous Sri Lankan adults. In particular, SA tend to have relatively high adiposity and increased disease risk compared with other ethnic groups for a given $\mathrm{BMI}^{(24-26)}$. In addition, SA develop diabetes mellitus and CVD at a younger age and perhaps more aggressively ${ }^{(27-30)}$.

A WHO expert committee has demonstrated the value of population-specific anthropometric cut-off values for Asian countries $^{(17)}$. In fact, few studies have pointed out much lower anthropometric cut-off values for SA compared with other major Asian population groups ${ }^{(25,31)}$. In Sri Lanka, the prevalence of diabetes was $10 \cdot 3 \%{ }^{(20)}$, and obesity-associated CVD have become the leading cause of death in the adult population ${ }^{(32)}$. The present results show that Sri Lankan adults have a high obesity-related CVD risk factor clustering at obesity levels lower than the existing cut-off levels proposed by the WHO for BMI and WC. The existing

Table 3. Anthropometric cut-off values for high obesity-related CVD risk*, diabetes mellitus, hypertension and dyslipidaemia for males and females (Sri Lankan adults)

(Area-under-the-curve (AUC) values and $95 \%$ confidence intervals)

\begin{tabular}{|c|c|c|c|c|c|c|c|c|c|}
\hline & \multicolumn{3}{|c|}{$\mathrm{BMI}\left(\mathrm{kg} / \mathrm{m}^{2}\right)$} & \multicolumn{3}{|c|}{ Waist circumference $(\mathrm{cm})$} & \multicolumn{3}{|c|}{ Waist-to-hip ratio } \\
\hline & Cut-off values & AUC & $95 \% \mathrm{Cl}$ & Cut-off values & AUC & $95 \% \mathrm{Cl}$ & Cut-off values & AUC & $95 \% \mathrm{Cl}$ \\
\hline \multicolumn{10}{|l|}{ Male } \\
\hline High obesity-related CVD risk & $20 \cdot 7$ & 0.71 & $0.68,0.73$ & 76.5 & 0.71 & $0.68,0.74$ & 0.89 & 0.68 & $0.66,0.71$ \\
\hline Dysglycaemia & $21 \cdot 2$ & 0.71 & $0.65,0.77$ & $85 \cdot 8$ & 0.74 & $0.69,0.81$ & 0.91 & 0.75 & $0.70,0.81$ \\
\hline Hypertension & 20.5 & 0.66 & $0.63,0.68$ & 76.5 & 0.67 & $0.65,0.70$ & 0.87 & 0.67 & $0.65,0.70$ \\
\hline Elevated TAG & $20 \cdot 7$ & 0.71 & $0.69,0.74$ & $77 \cdot 3$ & 0.72 & $0.69,0.74$ & 0.89 & 0.68 & $0.65,0.71$ \\
\hline Low HDL & $20 \cdot 9$ & 0.56 & $0.53,0.59$ & $75 \cdot 3$ & 0.54 & $0.51,0.57$ & 0.89 & 0.52 & $0.49,0.55$ \\
\hline \multicolumn{10}{|l|}{ Female } \\
\hline High obesity-related CVD risk & $22 \cdot 0$ & 0.71 & $0.69,0.73$ & $76 \cdot 3$ & 0.72 & $0.70,0.74$ & 0.85 & 0.68 & $0.66,0.70$ \\
\hline Dysglycaemia & $22 \cdot 7$ & 0.63 & $0.59,0.68$ & $77 \cdot 8$ & 0.66 & $0.62,0.70$ & 0.86 & 0.62 & $0.57,0.67$ \\
\hline Hypertension & $22 \cdot 0$ & 0.65 & $0.63,0.70$ & $76 \cdot 8$ & 0.66 & $0.64,0.68$ & 0.85 & 0.64 & $0.62,0.67$ \\
\hline Elevated TAG & $22 \cdot 8$ & 0.67 & $0.64,0.69$ & $75 \cdot 6$ & 0.68 & $0.66,0.71$ & 0.85 & 0.67 & $0.64,0.69$ \\
\hline Low HDL & $21 \cdot 7$ & 0.63 & $0.61,0.65$ & 74.5 & 0.62 & $0.60,0.65$ & 0.84 & 0.59 & $0.56,0.61$ \\
\hline \multicolumn{10}{|l|}{ All $\dagger$} \\
\hline High obesity-related CVD risk & 21.5 & 0.71 & $0.69,0.72$ & $76 \cdot 3$ & 0.71 & $0.70,0.73$ & 0.87 & 0.67 & $0.65,0.68$ \\
\hline
\end{tabular}

* 'High obesity-related CVD risk' implies the presence of two or more of TAG $\geq 1500 \mathrm{mg} / \mathrm{l}(1.7 \mathrm{mmol} / \mathrm{l})$ or specific treatment for hypertriacylglycerolaemia, HDL-cholesterol $(\mathrm{HDL}-\mathrm{C})<400 \mathrm{mg} / \mathrm{l}(1.03 \mathrm{mmol} / \mathrm{l})$ in males and $<500 \mathrm{mg} / \mathrm{l}(1.29 \mathrm{mmol} / \mathrm{l})$ in females or specific treatment for low HDL-C, systolic blood pressure $\geq 130 \mathrm{mmHg}$ or diastolic blood pressure $\geq 85 \mathrm{mmHg}$ or treatment for hypertension and fasting plasma glucose $\geq 1000 \mathrm{mg} / \mathrm{l}(5.6 \mathrm{mmol} / \mathrm{l})$ and/or $2 \mathrm{~h}$ post oral glucose tolerance test glucose $\geq 7.8 \mathrm{mmol} / \mathrm{l}$.

† Both males and females - only the cut-off value to identify high obesity-related CVD risk is shown for both females and males together. 
Table 4. Comparison of sensitivity and specificity for the new and pre-existing anthropometric cut-off values for overweight and obesity in the Sri Lankan population to predict obesity-related high CVD risk

\begin{tabular}{|c|c|c|c|c|}
\hline & $\begin{array}{c}\text { Sensitivity } \\
(\%)\end{array}$ & $\begin{array}{c}\text { Specificity } \\
(\%)\end{array}$ & $\begin{array}{l}\text { PPV } \\
(\%)\end{array}$ & $\begin{array}{l}\text { NPV } \\
(\%)\end{array}$ \\
\hline \multicolumn{5}{|c|}{$\mathrm{BMI}>21.5 \mathrm{~kg} / \mathrm{m}^{2 \star}$} \\
\hline Male & 60 & 73 & 55 & 77 \\
\hline Female & 70 & 62 & 55 & 76 \\
\hline All & 66 & 67 & 55 & 76 \\
\hline \multicolumn{5}{|c|}{$\mathrm{BMI}>23.0 \mathrm{~kg} / \mathrm{m}^{2} \dagger$} \\
\hline Male & 44 & 83 & 58 & 73 \\
\hline Female & 57 & 74 & 59 & 73 \\
\hline All & 52 & 78 & 59 & 73 \\
\hline \multicolumn{5}{|c|}{$\mathrm{BMI}>25.0 \mathrm{~kg} / \mathrm{m}^{2} \ddagger$} \\
\hline Male & 25 & 91 & 60 & 69 \\
\hline Female & 39 & 85 & 64 & 68 \\
\hline All & 34 & 88 & 63 & 69 \\
\hline \multicolumn{5}{|c|}{$W C>75 \mathrm{~cm}^{*}$} \\
\hline Male & 76 & 56 & 48 & 81 \\
\hline Female & 72 & 61 & 55 & 77 \\
\hline All & 74 & 59 & 52 & 79 \\
\hline \multicolumn{5}{|c|}{$W C>80 \mathrm{~cm} \S$} \\
\hline Male & 62 & 72 & 55 & 78 \\
\hline Female & 57 & 75 & 60 & 72 \\
\hline All & 59 & 74 & 58 & 75 \\
\hline \multicolumn{5}{|c|}{$W C>90 \mathrm{~cm} \|$} \\
\hline Male & 27 & 92 & 64 & 70 \\
\hline Female & 25 & 92 & 67 & 65 \\
\hline All & 26 & 92 & 66 & 67 \\
\hline \multicolumn{5}{|c|}{ WHR $>0.859$} \\
\hline Male & 87 & 34 & 42 & 83 \\
\hline Female & 67 & 60 & 52 & 73 \\
\hline All & 74 & 49 & 47 & 76 \\
\hline \multicolumn{5}{|c|}{ WHR $>0.90^{\star}$} \\
\hline Male & 60 & 65 & 48 & 75 \\
\hline Female & 43 & 81 & 60 & 68 \\
\hline All & 49 & 75 & 54 & 71 \\
\hline \multicolumn{5}{|c|}{ WHR $>1.0^{\star *}$} \\
\hline Male & $6 \cdot 7$ & $97 \cdot 8$ & 62.5 & $66 \cdot 0$ \\
\hline Female & 4.1 & 98.6 & 65.6 & $61 \cdot 0$ \\
\hline All & $5 \cdot 1$ & 98.3 & $64 \cdot 1$ & 62.9 \\
\hline
\end{tabular}

PPV, positive predictive value; NPV, negative predictive value; WC, waist circumference; WHR, waist-to-hip ratio.

${ }^{*}$ Newly derived cut-off value.

† Asian cut-off value for overweight ${ }^{(17)}$

$\ddagger$ WHO cut-off value for overweight ${ }^{(9)}$.

$\S$ International Diabetes Federation (IDF) cut-off value for women ${ }^{(23)}$.

\|I IDF cut-off value for men ${ }^{(23)}$.

1. WHO cut-off value for women ${ }^{(9)}$

${ }^{* *}$ WHO cut-off value for $\operatorname{men}^{(9)}$.

cut-off levels based on Caucasian data as well as the proposed cut-off levels for Asians have lower sensitivity in predicting obesity-related CVD risk among Sri Lankans.

The cut-off values derived using these data are consistent with the cut-off values presented by Misra et al. ${ }^{(19)}$ (BMI $21 \mathrm{~kg} / \mathrm{m}^{2}$; WC $78 \mathrm{~cm}$ (male), $73 \mathrm{~cm}$ (female)) for the Asian Indian population and the cut-off values for the prediction of diabetes proposed by Snehalatha et al. ${ }^{(18)}$ (BMI $23 \mathrm{~kg} / \mathrm{m}^{2}$; WC $85 \mathrm{~cm}$ (male), $80 \mathrm{~cm}$ (female)) for South Indians. The cut-off values derived for an Arabic population in Oman using similar methods to the present study have shown higher values for BMI (male $23.2 \mathrm{~kg} / \mathrm{m}^{2}$, female $26.8 \mathrm{~kg} / \mathrm{m}^{2}$ ), WC (male $80 \mathrm{~cm}$, female $84.5 \mathrm{~cm}$ ) and WHR (male 0.91, female 0.91) ${ }^{(33)}$. For Japanese adults, WC $>85 \mathrm{~cm}$ for males and $80 \mathrm{~cm}$ for females has been proposed to identify two components of the metabolic syndrome ${ }^{(34)}$. Since we have evaluated the highest sensitivity and specificity for $\geq 2$ components of the metabolic syndrome excluding the anthropometric variable, the WC cut-off value proposed here can similarly be used to identify those with the metabolic syndrome in Sri Lanka.

Based on the present data, and considering the similar data from Misra et al. ${ }^{(19)}$ from India, we propose a BMI of $21.5 \mathrm{~kg} / \mathrm{m}^{2}$ as the cut-off level for diagnosing overweight in Sri Lankan adults. In the absence of a firm basis for differentiating overweight and obesity, we considered the higher CVD risk and the necessity to be pragmatic in proposing a BMI cut-off value for obesity in Sri Lanka. Accordingly, we propose a BMI cut-off value of $>25 \mathrm{~kg} / \mathrm{m}^{2}$ for defining obesity in Sri Lankan adults. An Indian consensus statement also suggested a BMI of $>25 \mathrm{~kg} / \mathrm{m}^{2}$ as a cut-off value for obesity for Asian Indians ${ }^{(35)}$.

Although the present data suggest a strong association between obesity and CVD risk, prospective data on BMI, morbidity and mortality among SA are needed to confirm the effect of these associations on clinical outcomes. A WC cut-off value of $75 \mathrm{~cm}$ (or 30 inches) is proposed for both men and women based on the present findings. The WHR cut-off values proposed are 0.85 for women and 0.90 for men. WHR was least predictive of obesityrelated CVD risk in Sri Lankan adults (Table 3). Compared with BMI and WC, the calculation of WHR needs two relatively difficult measurements and hence can be subject to more errors. Therefore, BMI and WC may be used in preference to WHR for clinical and epidemiological purposes in Sri Lankan adults.

These data as well as data from other SA populations clearly demonstrate that SA have an increased risk for obesity-associated chronic diseases at lower BMI and WC compared with other ethnic groups ${ }^{(25-32)}$. Therefore, adoption of these findings has important public health implications in reducing diabetes and other obesity-related chronic diseases in the Sri Lankan and other SA populations. Although it may appear unrealistic to adopt such low anthropometric cut-off levels when compared with the global guidelines based on data for Western populations, these data highlight the need of ethnic- and population-specific information for public health action. Prospective studies on mortality and CVD incidence based on these new findings are urgently needed to further evaluate the implications of these findings. The authors would also like to make it clear that these proposed anthropometric cut-off levels and recommendations may not be applicable for non-SA populations.

\section{Conclusions}

The anthropometric cut-off values derived for Sri Lankan adults to predict high CVD risks were much lower than the existing cut-off values for Caucasians and those 
proposed by the WHO for Asians. To overcome the burden of high obesity-associated CVD and diabetes mellitus in Sri Lanka and other SA countries, accurate identification of atrisk populations is urgently needed. An application of anthropometric cut-off values derived here would help public health professionals and clinicians to offer ethnicspecific preventive and curative strategies to Sri Lankans and similar ethnic groups in regional countries and immigrant populations.

\section{Acknowledgements}

The National Science Foundation of Sri Lanka was the main source of funding for the Sri Lanka Diabetes and Cardiovascular Study. Additional support was provided from the Oxford Centre for Diabetes, Endocrinology and Metabolism, UK, and the National Institute for Health Research (NIHR) Biomedical Research Centre Programme. P. K. was a Commonwealth Postgraduate Scholar. We thank the Diabetes Association of Sri Lanka and the WHO Office in Colombo for the support for lipid assays. The authors thank all individuals and institutions who helped and worked for the Sri Lanka Diabetes and Cardiovascular Study. The authors declare no conflict of interest. P. K. designed the study; P. K. and M. A. R. J. carried out the statistical analyses. M. A. R. J., P. K. and D. R. M. were responsible for writing the manuscript. M. H. R. S. and D. R. M. supervised the work and contributed to the final editorial work.

\section{References}

1. James PT, Rachel L, Eleni K, et al. (2001) The worldwide obesity epidemic. Obes Res $\mathbf{9}, 228 \mathrm{~S}-233 \mathrm{~S}$.

2. Seidell JC (2000) Obesity, insulin resistance and diabetes - a worldwide epidemic. Br J Nutr 83, Suppl. 1, S5-S8.

3. World Health Organization (2009) Obesity and overweight. http://www.who.int/dietphysicalactivity/publications/facts/ obesity/en/index.html (accessed 25 April 2009).

4. Lean MEJ (2000) Is long-term weight loss possible? Br J Nutr 83, S103-S111.

5. Must A, Spadano J, Coakley EH, et al. (1999) The disease burden associated with overweight and obesity. JAMA 282, 1523-1529.

6. Peeters A, Barendregt JJ, Willekens F, et al. (2003) Obesity in adulthood and its consequences for life expectancy: a lifetable analysis. Ann Intern Med 138, 24-32.

7. Seidell J, Han T, Feskens E \& Lean M (1997) Narrow hips and broad waist circumference independently contribute to increased risk of non-insulin dependent diabetes mellitus. J Intern Med 242, 401-406.

8. Dipietro L, Katz LD \& Nadel ER (1999) Excess abdominal adiposity remains correlated with altered lipid concentrations in healthy older women. Int J Obes Relat Metab Disord 23, 432-436.

9. World Health Organization (2000) Obesity: Preventing and Managing the Global Epidemic, Report of a WHO Consultation on Obesity, WHO Technical Report 894, pp. i-xii, 1-253.

10. Deurenberg P, Yap M \& van Staveren WA (1998) Body mass index and percent body fat: a meta analysis among different ethnic groups. Int J Obes Relat Metab Disord 22, 1164-1171.
11. Lofgren I, Herron K, Zern T, et al. (2004) Waist circumference is a better predictor than body mass index of coronary heart disease risk in overweight premenopausal women. J Nutr 134, 1071-1076.

12. Esmaillzadeh A, Mirmiran P, Azizi F, et al. (2004) Waist-to-hip ratio is a better screening measure for cardiovascular risk factors than other anthropometric indicators in Tehranian adult men. Int J Obes 28, 1325-1332.

13. Cossrow N \& Falkner B (2004) Race/ethnic issues in obesity and obesity-related comorbidities. J Clin Endocrinol Metab 89, 2590-2594.

14. The DECODA Study Group (2003) Age and sex-specific prevalence of diabetes and impaired glucose regulation in 11 Asian cohorts. Diabetes Care 26, 1770-1780.

15. Mather HM \& Keen H (1985) Southall diabetes survey: prevalence of known diabetes. BMJ 291, 1081-1084.

16. McKeigue PM, Ferrie JE, Pierpoint T, et al. (1993) Association of early-onset coronary heart disease in South Asian men with glucose intolerance and hyperinsulinemia. Circulation 87, 152-161.

17. World Health Organization Expert Consultation (2004) Appropriate body mass index (BMI) for Asian populations and its implication for policy and intervention strategies. Lancet 363, 157-163.

18. Snehalatha C, Viswanathan V \& Ramachandran A (2003) Cutoff values for normal anthropometric variables in Asian Indian adults. Diabetes Care 26, 1380-1384.

19. Misra A, Vikram NK, Gupta R, et al. (2006) Waist circumference cutoff points and action levels for Asian Indians for identification of abdominal obesity. Int J Obes (Lond) 30, 106-111.

20. Katulanda P, Constantine GR, Mahesh JG, et al. (2008) Prevalence and projections of diabetes and pre-diabetes in adults in Sri Lanka - Sri Lanka Diabetes, Cardiovascular Study (SLDCS). Diabet Med 25, 1062-1069.

21. World Health Organization (1995) Physical Status: The Use and Interpretation of Anthropometry. Report of a WHO Expert Committee. WHO Technical Report Series no. 854, pp. 424-438. Geneva: World Health Organization.

22. Alberti KG, Zimmet P \& Shaw J (2006) Metabolic syndrome - a new world-wide definition. A consensus statement from the International Diabetes Federation. Diabet Med 23, 469-480.

23. Zweig MH \& Campbell G (1993) Receiver-operating characteristic (ROC) plots: a fundamental evaluation tool in clinical medicine. Clin Chem 39, 561-577.

24. Deurenberg P, Deurenberg-Yap M \& Guricci S (2002) Asians are different from Caucasians and from each other in their body mass index/body fat per cent relationship. Obes Rev 3, 141-146.

25. Deurenberg-Yap M, Schmidt G, van Staveren WA, et al (2000) The paradox of low body mass index and high body fat percentage among Chinese, Malays and Indians in Singapore. Int J Obes (Lond) 24, 1011-1017.

26. Lear SA, Toma M, Birmingham CL, et al. (2003) Modification of the relationship between simple anthropometric indices and risk factors by ethnic background. Metabolism 52, 1295-1301.

27. Ehtisham S, Crabtree N, Clark P, et al. (2005) Ethnic differences in insulin resistance and body composition in United Kingdom adolescents. J Clin Endocrinol Metab 90, 3963-3969.

28. UK Prospective Diabetes Study Group (1994) UK prospective diabetes study XII: differences between Asian, AfroCaribbean and white Caucasian type 2 diabetic patients at diagnosis of diabetes. Diabet Med 11, 670-677.

29. Chaturvedi N \& Fuller JH (1996) Ethnic differences in mortality from cardiovascular disease in the UK: do they persist in people with diabetes? J Epidemiol Community Health 50, 137-139. 
30. Joshi P, Islam S \& Pais P (2007) Risk factors for early myocardial infarction in South Asians compared with individuals in other countries. JAMA 297, 286-294.

31. Razak F, Anand SS, Shannon H, et al. (2007) Defining obesity cut points in a multiethnic population. Circulation 115, 2111-2118.

32. Mendis S (1998) Cardiovascular Research in Sri Lanka - A Review and Bibliography, pp. 1-135. Colombo: Ministry of Health.

33. Al-Lawati JA \& Jousilahti P (2008) Body mass index, waist circumference and waist-to-hip ratio cut-off points for categorisation of obesity among Omani Arabs. Public Health Nutr 11, 102-108.

34. Nishimura R, Nakagami T, Tominaga M, et al. (2007) Prevalence of metabolic syndrome and optimal waist circumference cut-off values in Japan. Diabetes Res Clin Pract 78, 77-84.

35. Misra A, Chowbey P, Makkar BM, et al. (2009) Consensus statement for diagnosis of obesity, abdominal obesity and the metabolic syndrome for Asian Indians and recommendation for physical activity, medical and surgical management. J Assoc Physicians India 57, 163-170. 